\title{
The role of recall time in producing hypermnesia
}

\author{
HENRY L. ROEDIGER III \\ Purdue University, West Lafayette, Indiana 47907 \\ and \\ LEIGH A. THORPE \\ University of Toronto, Toronto, Canada M5S 1A1
}

\begin{abstract}
In two experiments subjects presented with either words or pictures showed improved recall over three successive recall tests for both types of materials; partially replicating Erdelyi's finding of hypermnesia. However, these subjects did not recall more unique items than other subjects who received only one test equated in time with the three shorter ones. It is concluded that hypermnesia results from simply allowing subjects additional recall time. In a third experiment subjects were shown to recall additional information even after a long recall period employed during an experimental session. This surprising amount of item recovery during long recall periods is attributed to the use of subjective retrieval cues that are thought to function in a manner analogous to externally manipulated cues.
\end{abstract}

One topic that has sparked the interest of memory psychologists over the years is the problem of reminiscence or spontaneous recovery, the recall of seemingly forgotten information in the absence of any changes in the external retrieval environment. Whenever subjects are tested repeatedly on material without intervening opportunities to study the material, one finds that subjects recall new material on later tests that could not be recalled on earlier tests (e.g., Brown, 1923; Tulving, 1967). This phenomenon, the recovery of new material on repeated recall tests, is referred to as reminiscence in the present paper. In most studies employing multiple recall tests, the reminiscence on later trials is offset by forgetting of previously recalled information, so there is no net increase in recall on later trials. Usually total recall remains about the same or decreases slightly on the later tests (e.g., Donaldson, 1971; Tulving, 1967).

It has been reported occasionally that when subjects are allowed two successive recall periods for recently presented material, they actually recall more material on the second test than on the first (e.g., Ballard, 1913; Brown, 1923). There has been much controversy over the reliability of this finding (e.g., Ammons \& Irion, 1954; Buxton, 1943), and probably most investigators have ignored the phenomenon in theoretical and empirical accounts of memory because it seems so ephemeral. Recently, Erdelyi and his associates have

This paper was written while the first author was on leave at the University of Toronto. This research was supported in part by Grant A8632 from the National Research Council of Canada to Endel Tulving. We thank Katherine Golden, Debra Lean, and Christine McCormick for their experimental assistance. Requests for reprints may be sent to Henry L. Roediger, III, Department of Psychology, Purdue University, West Lafayette, Indiana 47907. provided an important new attack on this problem. Erdelyi and Becker (1974, Experiment 1) presented subjects with a series of 80 items to be remembered, 40 concrete nouns and 40 pictures of objects that could be easily named. Subjects were allowed three successive 7-min periods for recall of all the items from the list. In order to control for possible criterion changes over successive trials, subjects were required to write down 40 responses on each test, guessing when necessary to produce the 40 items. The basic finding was that recall of pictures increased over the three successive recall periods, while recall of words remained about the same. This incremental recall of pictures across successive tests was labeled hypermnesia. Erdelyi and Becker also reported that the hypermnesia effect was enhanced somewhat by providing intervals between the recall tests during which subjects were to think about the material. The finding of incremental recall or hypermnesia has also been referred to as "negative forgetting" (Erdelyi, Finkelstein, Herrell, Miller, \& Thomas, 1976), since recall seems to increase with the passage of time since original presentation. The implication has been drawn that the usual forgetting functions obtained since the time of Ebbinghaus may not be general (Erdelyi, Note 1).

Unlike earlier reports, the hypermnesia effect reported by Erdelyi and Becker (1974) is quite reliable. In a second experiment they employed a pure list design by presenting subjects 60 words or 60 pictures and giving them three successive tests. Once again, incremental recall or hypermnesia was found for pictures but not words. Madigan (1976) also reported improved recall for pictures but not words on a second test relative to a first test. Thus, the basic phenomenon is not in doubt, although its interpretation is. 
The hypermnesia phenomenon raises many interesting questions. Why have so few of the numerous experiments employing multiple recall tests shown similar increments in recall? How can our theories of memory and forgetting encompass this peculiar finding of improved recall with the passage of time between original presentation and later test? One possible reason that other studies failed to find hypermnesia is that they typically employed words or nonsense syllables as the to-be-remembered material, and Erdelyi and Becker (1974) reported that hypermnesia did not occur for words. Assuming that pictures are represented in an imaginal code, perhaps it is necessary for material to be coded in this format in order to obtain hypermnesia. The role of imagery was further implicated when Erdelyi et al. (1976) showed that hypermnesia occurred for concrete words when subjects were instructed to form mental images of the words at presentation. However, in light of other research, it seems unlikely that the difference in material or coding format is responsible for the variable reports of hypermnesia. For example, Erdelyi, Buschke, and Finkelstein (1977) showed that hypermnesia occurred for words that were never actually presented, but which were generated by subjects as responses to simple questions. Also, Buschke (1973, 1974) has shown impressive levels of item recovery in a selective reminding task with words as stimuli. Finally, there have even been reports of incremental recall or hypermnesia with word lists (Brown, 1923).

In the present experiments, we were concerned with the possible role of temporal factors in producing the hypermnesia effect. Most experiments showing incremental recall across test trials have employed relatively long recall periods for the successive tests, on the order of $5 \mathrm{~min}$ or more. On the other hand, many of the studies failing to find hypermnesia in multiple test-trial situations (e.g., Donaldson, 1971; Tulving, 1967) have used short recall periods, often less than $1 \mathrm{~min}$. It seems possible that one necessary, but not sufficient, condition for the hypermnesia effect is relatively long recall periods. It is clear that this is not the only important factor, since hypermnesia for words has not been found in a number of experiments employing 7-min recall periods (Erdelyi \& Becker, 1974; Erdelyi et al., 1976, 1977). One focus of the present research was examination of how hypermnesia is related to the amount of time allowed for recall.

A second and more interesting issue to be examined is the question of whether or not the usual hypermnesia manipulation of providing successive recall tests results in recall of more information than could have been recalled by subjects if they were given one long recall period of equal length. In conducting experiments on a different topic, one of us has had occasion to employ cumulative measures of recall by allowing subjects a very long recall period and asking them to draw a line under the last word recalled after fixed intervals during free recall (Roediger, 1978; Roediger, Stellon, \& Tulving, 1977). This procedure allows one to compare conditions in terms of both rate and asymptotic level of recall and to ascertain whether or not differences among conditions in recall change with increased recall time. One surprising aspect of using this procedure is the discovery that recall continues to increase for a very long time, much longer than one might have expected a priori. Since simply allowing subjects a good deal of time for recall enables them to recall a rather great amount of additional information, it may be that the use of successive recall periods as in the usual hypermnesia procedure does not really allow the subjects to recall any more items than could have been recalled in a single test, if it were equated in duration with the successive tests. Donaldson (1971, Experiment 3) compared recall during two 40-sec recall periods and one 80 -sec period and found no difference between the number of different words recalled in the two cases, but did not report hypermnesia in the condition receiving two tests. The first two experiments reported here compared multiple recall tests to a single test equated in time under conditions known to produce hypermnesia, or incremental recall. If hypermnesia results simply from providing subjects additional recall time, the phenomenon may be less surprising than has been assumed, since we have known for some time that subjects will often later recall items not previously accessible (e.g., Brown, 1923).

Subjects in the first experiment were shown a list of either 50 pictures or 50 words and then were tested by either having three successive recall tests or one long recall test equated in length with the three shorter ones. Subjects tested three times were told to recall the entire list each time, while subjects given the single long test were simply asked to recall the list once during the interval. In both cases subjects were told to draw a line under the last item recalled every minute. Interest was primarily centered on (1) how much hypermnesia occurred with different amounts of time in the conditions with three successive recall trials, and (2) whether or not subjects given three successive recall periods would recall more items than subjects given a single long period.

\section{EXPERIMENT 1}

\section{Method}

Subjects. Subjects were 100 University of Toronto undergraduates. Most served for pay, but about $25 \%$ of the subjects volunteered to serve as one way to receive bonus points in an introductory psychology course.

Design. There were four independent groups of subjects. Two groups saw pictures and two groups saw words at input. One group that received each type of material was tested in three successive 7 -min recall tests, while the other groups were tested with one $21-\mathrm{min}$ recall test. Thus, the design was a 2 by 2 between-subjects design where the factors were words vs. pictures at presentation and three vs. one recall test. 
Materials. Fifty pictures of easily named objects were drawn and placed on slides. Some examples of the objects are clock, umbrella, squirrel, fish, stagecoach, tree, anchor, microscope, and alligator. Subjects who saw words at presentation received the names of the 50 pictures.

Procedure. Subjects were tested in small groups. They were told that they would see a list of 50 pictures (or words) and that they would be asked to recall the list after hearing some further instructions. Subjects in the picture conditions were told that the pictures were all of simple objects and that they would be asked to write down the names of the pictures during the recall test. Both the words and pictures were presented at a 5-sec rate.

After the pictures or words had been presented, subjects received further instructions about how to recall the items. The instructions were intended to reduce recency effects. Subjects were told to recall the items in any order in columns on their recall sheets. They were also told that they would be instructed after every minute to draw a line under the last item recalled and to number the line as instructed ("Draw Line 3," etc.). Subjects were also told, "We are going to give you a rather long time to recall the pictures [words] : 7 [or 21] $\mathrm{min}$. This will seem like too much time and you will think you cannot recall any more pictures [words] before the recall period is up. But a lot of experiments have shown that if you just keep trying you can recall much more than you might think possible. So please keep trying your very best to recall the pictures [words], even when it gets very hard."

After the first $7 \mathrm{~min}$ of recall, subjects in conditions receiving the three successive recall periods were told to stop. Their recall sheets were collected and they were told that there would be a second recall period during which they were to recall again all the list items they could, both those recalled on the previous test and those not recalled. They were encouraged to try to increase their recall from the first test. The break lasted about $1 \mathrm{~min}$, and during the extra time not used for instructions subjects were told to let their minds wander freely. After the second 7-min recall period, these subjects were given similar instructions and attempted to recall as many list items as possible a third time.

Subjects who recalled during one long period were interrupted after 7 and $14 \mathrm{~min}$ and encouraged to keep trying even though they might feel that they could not recall any more items. This instruction lasted only 5-10 sec.

\section{Results and Discussion}

Presented in Figure 1 is recall of pictures or words

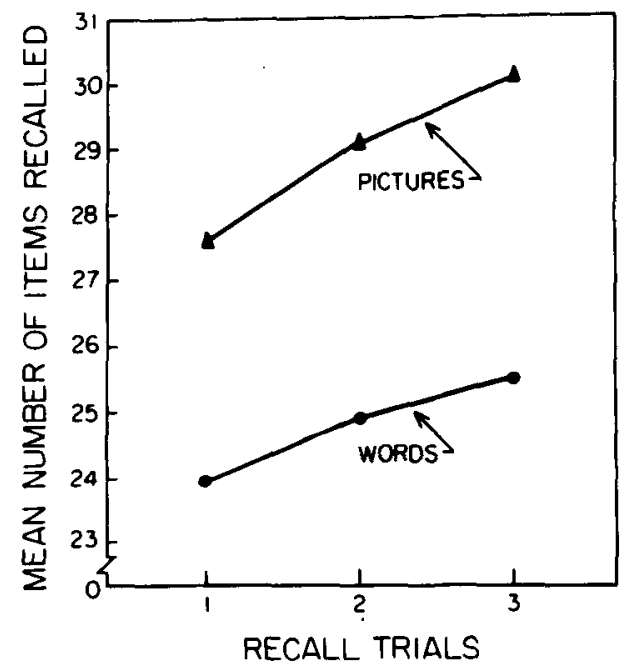

Figure 1. Mean recall of pictures and words across three successive recall trials in Experiment 1.

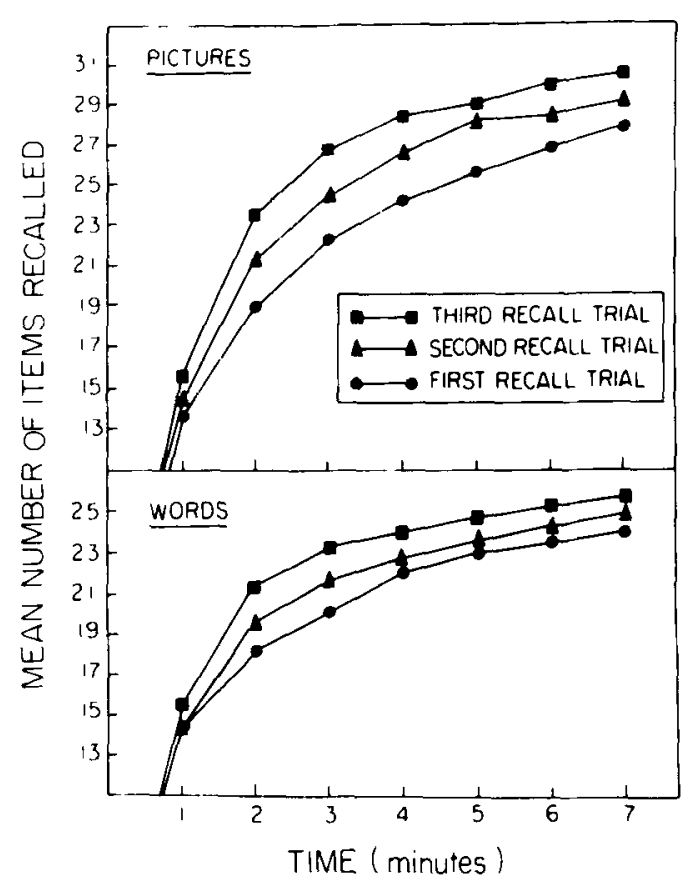

Figure 2. Mean cumulative recall of pictures (top panel) and words (lower panel) on three successive recall trials in Experiment 1.

by the two groups of subjects who were given three successive recall tests. With one exception, the typical outcome was replicated. Pictures were better recalled than words on the three tests $[F(1,48)=5.04$, $p<.05]$, and recall improved across the three tests $[F(2,96)=19.30, p<.001]$. Unlike the results of Erdelyi and Becker (1974), there was no interaction between pictures vs. words and recall test $[F(2,96)=1.65$, n.s. $]$. When analyzed separately, there was reliable variation in recall of both pictures $[F(2,48)=14.02, p<.001]$ and words $[F(2,48)=5.71$, $\mathrm{p}<.011$. Thus, in the present study hypermnesia, or incremental recall, was found for both pictures and words.

One focus of interest in this research is how hypermnesia is affected by the length of the period subjects are allowed for recall. Results relevant to this issue are found in Figure 2, where cumulative recall curves for each of the three successive tests are displayed separately for subjects presented with pictures (top panel) and words (bottom panel). The results presented in Figure 1 are those after all $7 \mathrm{~min}$ of recall. From Figure 2 it does appear that the hypermnesia effect depends on the amount of recall time subjects are allowed. Had subjects been allowed only 1-min recall periods, there would have been little or no evidence for hypermnesia, especially with words. Since the recall periods in many experiments employing multiple recall trials have been even less than $1 \mathrm{~min}$, it is not surprising that these experiments failed to find hypermnesia (e.g., Donaldson, 1971; Tulving, 1967). There are, of course, other differences between those experiments and the present one, but it does appear 
Table 1

Mean Number of Items Forgotten (CN) and Recovered (NC) Between Successive Test Trials

\begin{tabular}{cccc}
\hline \multirow{2}{*}{ Pictures } & & \multicolumn{2}{c}{ Test Trials } \\
& & $1-2$ & $2-3$ \\
\hline \multirow{2}{*}{ Words } & $\mathrm{CN}$ & 1.8 & 1.7 \\
& $\mathrm{NC}$ & 3.2 & 3.0 \\
& $\mathrm{CN}$ & 1.5 & 1.2 \\
\hline
\end{tabular}

from the results in Figure 2 that length of the recall period is one factor determining hypermnesia.

Another interesting fact to be noted from Figure 2 is that the greatest difference among the successive recall tests actually occurs at the intermediate recall times, roughly $2-4 \mathrm{~min}$. Thus, if one is interested in obtaining hypermnesia, one should use recall periods of this length, at least under presentation conditions similar to those used in this experiment. After the intermediate recall times, the functions appear to converge again, although as already noted the differences at the end of the retention interval are still reliable. It is interesting to speculate as to whether the hypermnesia effect would be further attenuated with even greater recall time.

One further analysis is of interest in recall of subjects given successive recall tests. Presented in Table 1 are the mean values of intertest forgetting (items Correctly recalled on the first test and then Not recalled on the second, or the $\mathrm{CN}$ component of recall) and intertest recovery, or the NC component of recall. The $\mathrm{CN}$ components of recall are slightly greater for pictures than words, but there are more opportunities for intertest forgetting with pictures since initial recall is greater. The NC, or reminiscence, component is greater for pictures than words, despite the fact that subjects presented with pictures recalled more items during the initial period and thus had fewer remaining targets during the later recall tests than subjects presented words. On the second test subjects recalling pictures recalled $14 \%$ of items not recalled on the first test, while on the third test these subjects recalled $16 \%$ of the items not recalled on either of the first two tests. The comparable figures for subjects presented with vords were $9 \%$ and $8 \%$ on the second and third tests, espectively. Thus, despite the fact that there was no eliable interaction between type of material and recall ests in terms of the total number of words recalled, when conditionalized on recall opportunities, it does ieem that picture presentation allowed greater item ecovery (reminiscence) than word presentation.

Of primary interest in this experiment is whether or ot subjects given three recall tests recalled more items han did subjects given a single recall test equated in sverall length with the three shorter ones. Presented $\mathrm{n}$ Figure 3 are cumulative recall curves over $21 \mathrm{~min}$ for subjects in all four conditions. Subjects given three recall tests were scored for these purposes only on the unique items they recalled. That is, they were given credit the first time they recalled an item and then repetitions of the item in later recall tests were not counted. Only reminiscent items were counted on the later tests. The results portrayed in Figure 3 indicate that recall did not differ between subjects given one long recall test and subjects given three successive tests as in the usual hypermnesia manipulation. In fact, recall was slightly greater for subjects having one test, although this difference was not reliable $[F(1,96)<1]$. The superiority of picture to word recall was reliable $[F(1,96)=21.06, \quad p<.001]$, and the interaction between type of material and number of tests was not reliable. Since greater recall was not achieved with the successive tests of the hypermnesia manipulation than with a single test equated in time, it appears that hypermnesia results simply from increasing recall time. This theme is elaborated in the General Discussion.

One more finding is worthy of note. In studying hypermnesia, Erdelyi and his colleagues have typically used a forced recall procedure to insure that improvements in recall over successive tests are not due to a shifting criterion. This procedure was not adopted in the present study, but intrusions were examined to infer criterion differences. If subjects were guessing differentially in the different conditions, this should be reflected in intrusion rates. Scoring correct items in this experiment was performed using a liberal criterion, because subjects in the picture conditions did not always arrive at the label for the picture that we had intended. To take the most obvious example, a number of subjects who saw the picture of the alligator wrote down crocodile. This was, of course, considered a correct response. However, the same criterion was used for

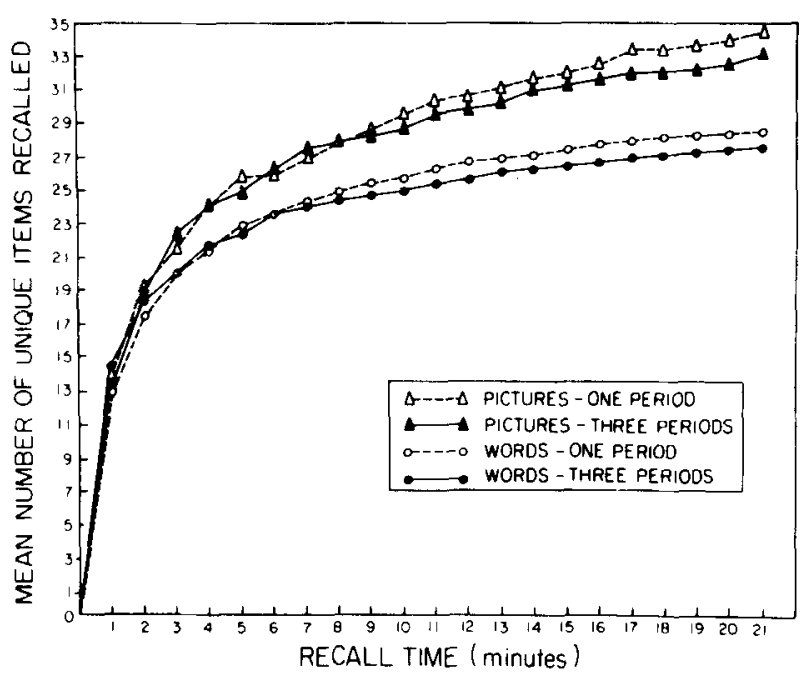

Figure 3. Mean cumulative recall of unique items for subjects presented pictures or words and given either three 7-min tests or one 21-min test in Experiment 1 . 
recall of words as pictures. So subjects seeing the word list were also given credit for crocodile, even though they had seen the word alligator at presentation. There were relatively few of these cases. The number of extralist intrusions (recalled words that did not seem to relate to any presented item) was quite small, averaging 1.3 for pictures and 1.2 for words. There was no increase in the number of intrusions across successive tests, so apparently the observed hypermnesia in this situation without forced recall was not due to a shifting criterion.

\section{EXPERIMENT 2}

The primary finding of the first experiment was that subjects allowed a single 21 -min recall test recalled as many items as subjects given three 7-min tests, whether words or pictures were presented. Since this finding is based on a failure to reject the null hypothesis, further evidence is offered from a separate experiment. Another point of interest from the first experiment is the finding of incremental recall, or hypermnesia, across successive tests with word stimuli. The second experiment reported here, which was actually performed prior to the one just reported, involved presentation of 30 high-imagery and 30 low-imagery words to four groups of subjects. Two groups of subjects were given instructions to try to form a mental image for each presented word, while the other two groups of subjects were asked to think of the meaning of the words as they were presented, with the suggestion that thinking of associates would be useful. One group receiving each type of instruction was given three successive 7-min tests, while the other group was given a $21-\mathrm{min}$ test. It was thought that subjects given imagery instructions would show greater hypermnesia for high- than for low-imagery words, while the reverse would be the case for subjects given the semantic instruction. The 21 -min conditions were employed as a control for total recall time.

\section{Method}

The method was quite similar to that of the previous experiment. The subjects were 120 Purdue University undergraduates serving as part of an introductory psychology course requirement. Thirty subjects were assigned to each of four conditions and tested in groups of 5 to 10 . In their initial instructions, subjects were told that they would hear 60 words and be asked to recall them later. Subjects in all four conditions were told that they would be provided with a technique that should better enable them to recall the words. Two groups of subjects were told that they should attempt to form mental images of the words, as this has been shown to be an effective memory strategy. They were told that this might be difficult for some of the words since they did not refer to concrete objects, but that they should try their best to form an image for all the words. The other two groups of subjects were told that the effective strategy was to think carefully about the meaning of the words as they were presented. It was suggested that thinking of associates of the to-be-remembered words would be an effective strategy for activating the meaning of the words. These conditions are referred to as the imagery and semantic conditions, respectively.
The 60 words were nouns taken from the norms of Paivio, Yuille, and Madigan (1968). The 30 high-imagery words had a mean imagery rating of 6.26 , while the 30 low-imagery words had a mean rating of 4.30 . (The rating scale ranged from 1 to 7. ) The two sets of words were equated for meaningfulness, frequency, and length. The items were presented in a random order at a 5 -sec rate by a tape recorder.

After the words were presented, subjects heard instructions similar to those used in the first experiment. Two groups of subjects (one given the imagery instruction, the other given the semantic instruction) were given three successive 7-min recall tests. The other two groups were given a single $21-\mathrm{min}$ recall test. Details of the instructions were the same as those used in Experiment 1.

\section{Results and Discussion}

There was no overail difference in recall between subjects receiving the imagery and semantic instructions, nor did this variable interact reliably with the imagery value of the words. Therefore, results were combined from these two conditions and this variable will not bc further discussed.

Presented in Figure 4 is the mean number of words recalled by subjects given three recall tests, with values for high-and low-imagery words plotted separately. There was reliable variation due to the imagery value of the words $[F(1,354)=11.83, p<.001]$ and due to recall tests $[F(2,354)=5.44, p<.01]$, and a reliable interaction between factors $[\mathrm{F}(2,354)=11.69$, $\mathrm{p}<.001]$. Thus, hypermnesia or incremental recall was found for words, replicating one result of the first experiment, but the effect was somewhat greater for high-than low-imagery words.

Presented in Figure 5 are the cumulative recall curves for the three recall tests for both high-and low-imagery words. Results were combined over the imagery variable since both sets of words showed hypermnesia. The results in Figure 5 are representative of the outcome for both high- and low-imagery words. As was seen in the comparable results from the first experiment, the least improvement among the successive recall tests is evident at the $1-\mathrm{min}$ interval. The slight convergence evident later in the recall period was

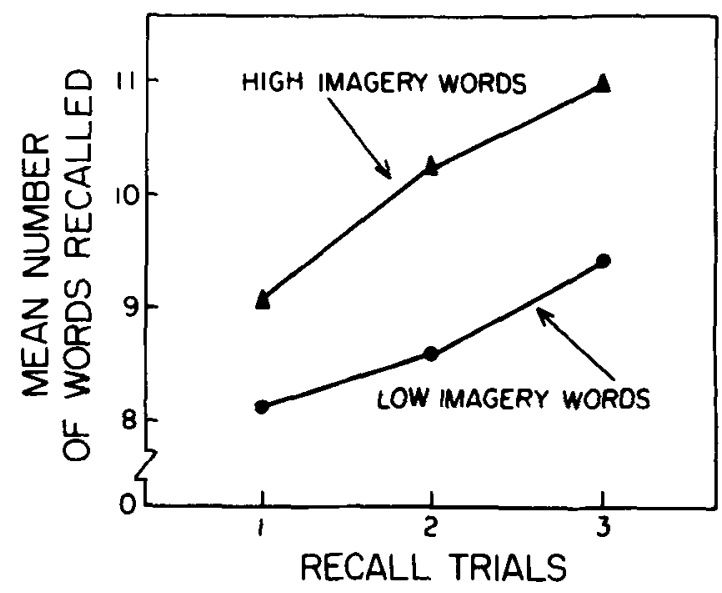

Figure 4. Mean recall of high- and low-imagery words for subjects tested on three successive recall trials in Experiment 2. 


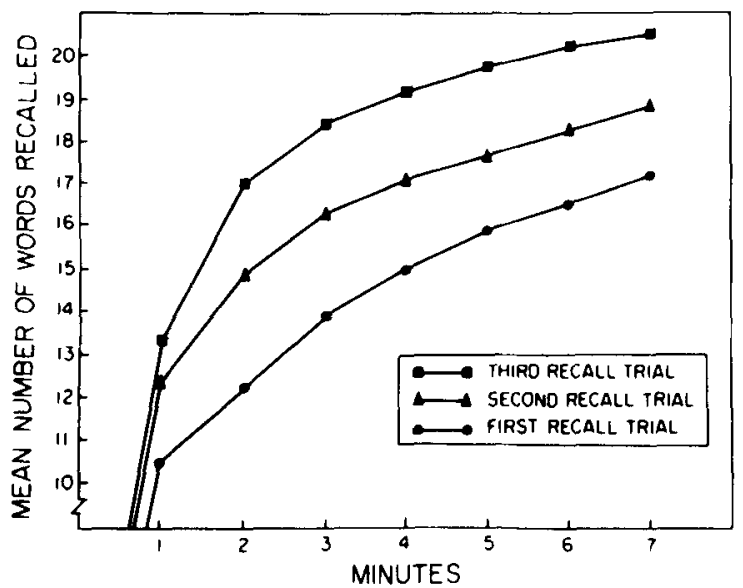

Figure 5. Mean cumulative recall of words on three successive recall trials in Experiment 2.

less than that in the results of Experiment 1. The hypermnesia effect with words was somewhat stronger in this experiment than in the first in terms of absolute differences, perhaps because of the instructions encouraging imaginal and semantic processing (cf. Erdelyi et al., 1976, 1977).

Subjects given three recall periods did not recall reliably more words than subjects given one recall period equated in length, the mean number of words recalled being 22.6 and 22.5 in the two conditions, respectively $[F(1,116)<1]$. Surprisingly, there was also no reliable effect of high-vs. low-imagery words $[F(1,116)=2.06, p>.10]$. However, these findings are complicated by a marginally reliable interaction between the variables that is shown in Figure 6 $[F(1,236)=3.84, .10>p>.05]$. For low-imagery words, one recall period was slightly superior to three (11.2 vs. 10.5 words recalled), while for high-imagery words there was a slight reversal of this pattern (12.1 words recalled with three periods, 11.3 words recalled with one period). However, even for the high-imagery words, the difference between the means in terminal recall levels was not reliable by a Newman-Keuls test, so the finding that three successive recall tests does not allow better recall than one long test was replicated.

\section{EXPERIMENT 3}

The results of the first two experiments show that recall continues to increase slowly but steadily when subjects are given very long recall periods and encouraged to keep trying. This observation is in agreement with the idea that forgetting is due to inaccessibility of information rather than its unavailability (Tulving \& Pearlstone, 1966). Even without the aid of external retrieval cues, subjects recall more words when given additional time, which argues that the difficulty is in retrieving the information, and that it has not been "lost" from the store. This increased recall with extra time accords with the observation that sometimes subjects previously tested in an experiment will say, on a later casual meeting, that they remembered several more words from the experiment just as they were leaving, or later that night, or the next day. Other investigators have reported similar informal observations to us. Perhaps it is the case that, given much more time, subjects could recall additional information from a set of experimental materials even after the formal testing session is completed.

The third experiment was a pilot study attempting to gather more systematic observations on this long-term reminiscence phenomenon. Subjects were presented with a word list either once or twice at a very slow rate and then were given a long recall period. After subjects had recalled the list during this period, they were asked to keep trying to recall the words later and were offered a monetary reward as an incentive.

\section{Method}

The subjects were 24 Purdue graduate and undergraduate students recruited from the first author's courses in cognitive psychology. They were paid for their participation. Upon reporting to the experiment, subjects were informed that they would be asked to study and recall a list of 60 words. Subjects were told that the words would be presented at a slow rate and that they should study them carefully. The subjects were given a brief lecture on effective memory strategies that they were to use when studying the words. They were told that forming mental images or "mental pictures" was one very effective way of increasing recall and that another effective technique involved using the semantic relations of words. Subjects were told that they could improve their recall with the latter technique by thinking carefully of the meaning of each word, and it was suggested that if they tried to generate associates to the words or to use them in constructing sentences and stories, they would be more likely to remember them later.

The subjects were tested in two groups of 12 . Twelve unique

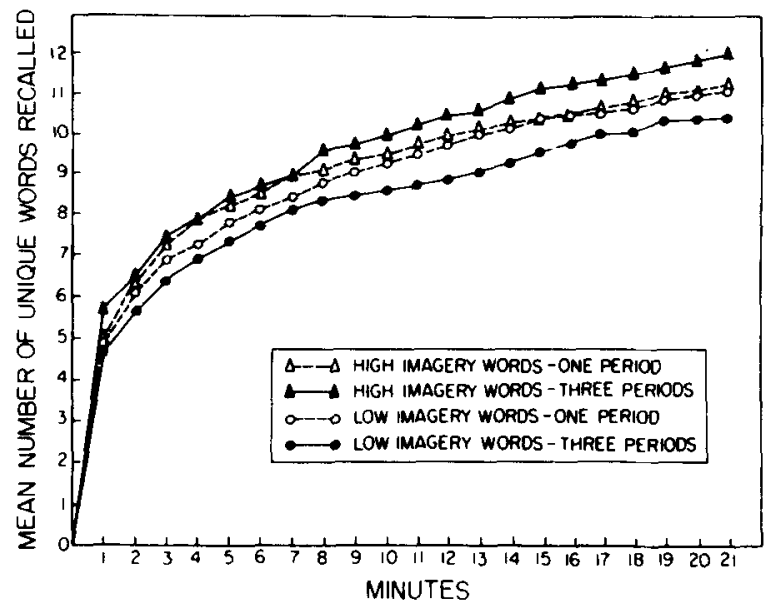

Figure 6. Mean cumulative recall of unique items for subjects given either three 7 -min tests or one 21 -min test in Experiment 2. 
lists of 60 words were constructed largely from high-imagery words in the Paivio, Yuille, and Madigan (1968) norms, but other words referring to common objects had to be included in order to obtain the necessary 720 -word pool. Each subject in one condition was given a different list. The words were all printed on index cards and subjects presented the cards to themselves one at a time by removing the top card from the pile and studying the next one on instructions from the experimenter. The presentation rate was $8 \mathrm{sec} /$ word. One group of subjects saw the list once, while the second group saw each word twice. For the latter group, the words were presented in the same order on both study trials.

After the list was presented, subjects were asked to recall as many United States presidents as possible for $2 \mathrm{~min}$ in order to eliminate recency effects from recall. Then subjects were instructed to recall as many words from the list as possible in any order by recording them in columns on their recall sheets. Subjects were asked to draw a line under the last word recalled every minute, and after 6 and $12 \mathrm{~min}$ subjects were encouraged to keep trying. The recall period lasted $15 \mathrm{~min}$.

After the recall test, subjects were told that they should try to continue recalling the words after they had left the test session. They were told that this was the important part of the project and were encouraged to attempt recall of additional words for the next 2 months (the remainder of the term). Subjects were told that they would receive 50 cents for each additional word recalled. They were periodically reminded of their task and encouraged to keep trying during class meetings.

\section{Results and Discussion}

Cumulative recall curves for the two groups of subjects are presented in Figure 7. After 15 min subjects who saw the list once had recalled a mean of 32.4 of the 60 words, while subjects who saw the list twice had recalled 39.8. There was recovery of additional items after the subjects left the experimental session, but the number of words recovered was not terribly impressive. Subjects seeing the items presented once recovered a mean of 2.0 words after the session, while subjects who saw the list twice recovered only 1.1 . In both cases subjects recovered 7\% of words not recalled in the initial $15-\mathrm{min}$ period. The mean number of additional words recalled is not entirely representative

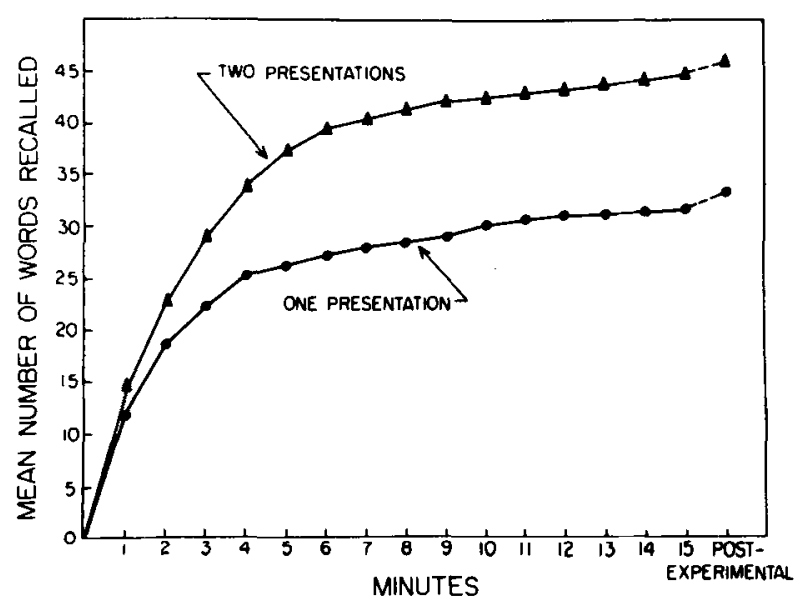

Figure 7. Mean cumulative recall of once- and twicepresented words and words recalled after the experimental session (postexperimental) in Experiment 3. of performance because the distributions of recall scores were markedly skewed, especially for subjects with two presentations. In that condition two subjects recalled five and four additional words, four recalled one, and the other six recalled none.

It is clear from the results in Figure 7 that even a long recall period does not exhaust the information that people can recall about a list. They are still sometimes able to recall additional information, even without the aid of external retrieval cues. As in the previous experiments, given more time subjects recall more words. However, the number of additional words recalled in this experiment was not too impressive and certainly was below our expectations given the occasional subjective reports we had collected. There are at least two reasons for this. First, the initial recall period was much longer than in most experiments, and thus words likely to be subject to reminiscence were already recalled. Second, our initial expectations were doubtless influenced by a subject-selection artifact. We only heard reports from subjects who in fact recalled a number of additional items; subjects who recalled no more items after an experiment was over did not stop us in the hall to relate this information.

Most of the additional words recalled after the experimental session were recalled on the night of the experiment. Very few were recalled later. Most subjects said that they lost interest and did not take the time to attempt recall after the first night, feeling that the task was hopeless. One way in which the procedure could be improved in future experiments is to have subjects return and be required to keep trying to recall the words, rather than simply to leave them on their own. If this is done, it may be the case that requiring subjects to recall the entire list again would affect recall differently from just having them keep trying to recall additional items. Perhaps in this case there would be a difference between the hypermnesia manipulation and just allowing subjects additional time, unlike the finding in the first two experiments reported here.

\section{GENERAL DISCUSSION}

The results of these experiments indicate that hypermnesia, increased recall on successive recall tests, is attributable to increased time permitted for recall. When subjects allowed three successive recall tests are compared to subjects who are given only one extended test of equal length, there is no difference in the total number of different items recalled. This finding may serve to alter the way hypermnesia is conceptualized. Hypermnesia, or incremental recall, appears to be no more surprising than the fact that, under certain conditions, subjects will recall more material when allowed a $10-\mathrm{min}$ recall period than when given a $5-\mathrm{min}$ recall period.

The present experiments allow some specification 
as to the conditions under which hypermnesia is likely to be observed. First, the amount of time allowed for each recall test should at least be several minutes long with the amount and types of material typically used. By measuring recall cumulatively as in the present experiments, it is possible to assess the appropriate amount of recall time for particular situations. It is likely that many studies have failed to report hypermnesia because the amount of time allowed for successive recall tests was quite limited (e.g., Donaldson, 1971; Tulving, 1967). A second requirement for hypermnesia is that cumulative recall functions for the particular conditions not have asymptoted during the initial recall period. If the first recall test lasts so long that subjects have already reached asymptote, then no increments are to be expected from allowing additional tests. This may be the reason that other researchers have not found hypermnesia for words (e.g., Erdelyi \& Becker, 1974; Madigan, 1976).

Two other findings are compatible with the interpretation of hypermnesia as due to extended recall time. Erdelyi and Becker (1974) reported that when subjects were given a 5 -min interval between successive recall tests and instructions to think about the material during this period, hypermnesia increased. The additional 5 min between tests probably served to increase the effective recall time. In another experiment, Shapiro and Erdelyi (1974) were concerned with the issue of whether or not hypermnesia occurs because of possible practice effects in taking recall tests. They presented two groups of subjects with a list of pictures and words and then tested one group $30 \mathrm{sec}$ after presentation, while the other group was tested $5 \mathrm{~min}$ after presentation. Each group received only a single $7-\mathrm{min}$ test. The results showed that subjects tested after $5 \mathrm{~min}$ recalled more pictures than did subjects tested after $30 \mathrm{sec}$, but recall of words did not differ between the two groups. This would seem to be a case of hypermnesia for pictures uncontaminated by a confounding with overall recall time, since both groups nominally received only $7 \mathrm{~min}$ for recall. However, the subjects for whom recall was delayed were allowed to think about the list during this interval, so effectively, this added $5 \mathrm{~min}$ of recall time for the group that showed increased recall of pictures. There is no evidence that independent groups of subjects will show hypermnesia when allowed a single test after various periods of time that are filled with an interpolated activity; in fact, the evidence suggests that forgetting will occur and will increase with delay under these conditions (Ammons \& Irion, 1954).

The present results and those of others allow us to make several statements about our customary methods of measuring recall. It is the usual practice for memory psychologists to measure recall after a fixed and usually fairly short time period and assume that the differences obtained among conditions represent accurately the differences in memorability produced by the different experimental conditions. This logic must be called into question. As Brown (1923) pointed out years ago, a single recall test is an imperfect indicator of memory. The amount of time allowed for recall may turn out to be a critical variable in many situations and may help account for some of the puzzling situations where results do not easily replicate. It may be that there were different amounts of recall time in the different experimental situations and that this factor was overlooked. In the first experiment, if $1-\mathrm{min}$ recall tests had been used, one would have reached the conclusion that there was no hypermnesia for words or pictures, while if 2-or 3-min tests had been used, one would have concluded that there was a quite healthy hypermnesia effect for both words and pictures. At the end of the 7 -min test, there was a moderate amount of hypermnesia. By employing the simple expedient of cumulative recall measures, it is quite easy to examine the effects of recall time on differences among experimental conditions.

Most investigators studying item recovery have used multiple tests rather than a single long test with recall measured cumulatively. The results of Experiments 1 and 2 show that these two procedures produce equivalent amounts of item recovery, which is the primary observation of interest in such experiments. A possible disadvantage from using one prolonged test is that recall cannot be divided into components reflecting intertest forgetting and recovery ( $\mathrm{CN}$ and $\mathrm{NC})$ as is possible with multiple tests. While item recovery can be observed with a long recall period, forgetting of items cannot be observed. However, we do not think this is a drawback. Recall of an item (experience) indicates that it is available and potentially accessible. The fact that the subject may not recall it during some later brief time period that we arbitrarily define as a recall test may be of little interest. Buschke (1973) has shown that with repeated recall attempts, these forgotten items will be recovered. Thus, there seems little reason to prefer the usual procedure of employing multiple recall tests to a single extended recall test of equal duration.

Even if the hypermnesia effect reduces to the phenomenon of increased recall with extended recall time, as we are arguing, the basic phenomenon would still seem to be interesting and important. Although it is probably not the case that recall of an entire list increases since time of original presentation when amount of recall time per test is equated across delays, it is the case that there is a great deal of recovery of individual items or reminiscence. Why is it that after sitting for $10 \mathrm{~min}$ having recalled no new items, subjects may suddenly recall three or four items very quickly? Investigators of hypermnesia and reminiscence are usually mute about theories underlying the effect, preferring to discuss the results in terms of the need 
to distinguish between available and accessible memories and to emphasize the importance of retrieval processes in theories of memory. One quite natural theoretical suggestion to account for reminiscence is Estes's (1955) stimulus sampling theory, that was originally applied to the similar problem of spontaneous recovery following extinction of a conditioned response. By this view reminiscence occurs due to sampling of elements from memory with the particular elements sampled changing with increased delays due to inherent variability in the population of elements being sampled. More recently, it has been similarly suggested that recall is a sampling-with-replacement process where recall of information does not eliminate this particular information from consideration on future retrieval attempts (Rundus, 1973; Shiffrin, 1970). Further, it has been suggested that the act of recall makes it more likely that recalled information will be repeatedly retrieved to the relative exclusion of new information (Roediger, 1974; Rundus, 1973). It may be that reminiscence, or recall of new information after the passage of time, may be due to the gradual release of the inhibition produced by the act of recall (Madigan, 1976).

Subjects given three successive recall periods may actually be retrieving information in much the same way as are subjects given the single long test. That is, subjects in the latter condition may be repeatedly retrieving information about items just as do subjects with the three successive tests, although of course, these items are not overtly recalled. At any rate, there was no difference in recall of different items on the two types of tests in the first two experiments, despite the fact that subjects given three tests had to spend some of the $21 \mathrm{~min}$ overtly recalling previously recalled items. Perhaps subjects given only one test were similarly engaged, although the repeatedly retrieved items were only written once. Nelson and Macleod (1974) have shown that subjects given two successive tests of fairly short duration do not recall more new or old words on the second test when they are told to recall only the one type of word than when they are asked to recall both types.

One further suggestion, complementing the remarks made above, may provide a slightly different attack on the problem of reminiscence. It may be useful to relate this problem to situations where recall increments are produced by external manipulation of retrieval cues. It is well known that presentation of various sorts of retrieval cues, such as category names for a categorized word list, often produces dramatic increments in recall relative to that obtained from subjects engaged in free recall (e.g., Tulving \& Pearlstone, 1966; Tulving \& Psotka, 1971). Although the external retrieval environment is not changed when subjects free recall items for long periods of time as in the experiments reported here, it may be that the same underlying dynamics are responsible for the improvements in recall. That is, subjects may themselves be producing what could be called subjective retrieval cues that in turn allow recall of items in the list. Such a possibility has been suggested by Bransford, McCarrell, Franks, and Nitsch (1977) and by Tulving (1974). This idea is speculative, but has the advantage of trying to relate increments in recall in this rather puzzling situation to similar increments in the cued recall situation which is somewhat better understood.

\section{REFERENCE NOTE}

1. Erdelyi, M, H. Has Ebbinghaus decayed with time? Paper presented at the meeting of the Psychonomic Society, Washington, D.C.. November 1977.

\section{REFERENCES}

Ammons. H. \& IRIon. A. L. A note on the Ballard reminiscence phenomenon. Joumal of Experimental Psychology. 1954. 48. 184-186.

Ballard, P. B. Oblivescence and reminiscence. British Journal of Psychology Monograph Supplements, 1913, 1, No. 2.

BRANSFORd, J. D.. MCCARRELl, N. S., Franks, J. J., \& Nitsch. K. E. Toward unexplaining memory. In R. Shaw \& J. D. Bransford (Eds.). Perceiving, acting, and knowing. Hillsdale. N.J: Lawrence Erlbaum. 1977.

Brown, W. To what extent is memory measured by a single recall? Journal of Experimental Psychology. 1923. 6. 377-382.

BusCHKE, $H$. Selective reminding in the analysis of learning and memory. Joumal of Verbal Leaming and Verbal Behavior, 1973, 12. 543-550.

BuschKe. H. Spontaneous remembering after recall failure. Science. 1974, 184. 579-581.

Buxton. C. E. The status of research in reminiscence. Psychological Bulletin. 1943, 40. 313-340.

Donaldson, W. Output effects in multitrial free recall. Journal of Verbal Learning and Verbal Behavior, 1971, 10, 577-585.

ERdely1. M. H., \& Becker, J. Hypermnesia for pictures: Incremental memory for pictures but not words in multiple recall trials. Cognitive Psychologv. 1974. 6. 159-171.

Erdelyi. M. H.. Buschke, H., \& Finkelstein. S. Hypermnesia for Socratic stimuli: The growth of recall for an internally generated memory list abstracted from a series of riddles. Memory \& Cognition, 1977. 5. 283-286.

Erdelyi, M. H.. Finkelstein. S., Herrell, N., Miller. B., \& Thомas, J. Coding modality vs. input modality in hypermnesia: is a rose a rose a rose? Cognition. 1976. 4. 311-319.

Estes, W. K. Statistical theory of spontaneous regression and recovery. Psychological Review, 1955, 62, 145-154.

Madigan. S. Reminiscence and item recovery in free recall. Memory \& Cognition, 1976, 4. 233-236.

Nelson. T. O., \& MacLeod, C. M. Fluctuations in recall across successive test trials. Memory \& Cognition. 1974. 2. 687-690.

Paivio. A.. Yuille. J. C., \& Madigan, S. Concreteness, imagery, and meaningfulness values for 925 concrete nouns. Joumal of Experimental Psychology Monograph Supplement, 1968. 76(1. Part 2).

Roediger. H. L. Inhibiting effects of recall. Memory \& Cognition, 1974, 2. 261-269. 
Ruediger. H. L. Recall as a self-limiting process. Memon \& Cogmition, 1978, 6. 54-63.

Roediger. H. L.. Stellon, C.. \& Tulving, E. Inhibition from part-list cues and rate of recall. Journal of Experimental Psychology: Human Learning and Memony. 1977, 3. 174-188.

Rindus. D. Negative effects of using list items as recall cues. Journal of Verbal Learning and Verbal Behavior. 1973, 12, 43-50.

Shapiro. S. R.. \& Erdelyi. M. H. Hypermnesia for pictures but not words. Journal of Experimental Psychology. 1974. 103. 1218.1219.

ShIfFRIN. R. M. Memory search. In D. A. Norman (Ed.). Models of human memony. New York: Academic Press. 1970. Pp.375-447.

Tulving. E. The effects of presentation and recall in free recall learning. Journal of Verbal Learning and Verbal Behavior, 1967, 6, 175-184.
Tulving, E. Cue-dependent forgetting. American Scientist, 1974. 62. 74-82.

Tulving. E.. \& Pearlstone, Z. Availability versus accessibility of information in memory for words. Journal of Verbal Learning and Verbal Behavior. 1966, 5, 381-391.

Tulving, E. PsotKa, J. Retroactive inhibition in free recall: Inaccessibility of information available in the memory store. Journal of Experimental Psychology. 1971. 87. 1-8.

(Received for publication December 14, 1977; accepted January 30,1978 .) 